\title{
Users’ Adoptive Behavior towards the ERP System
}

\author{
Chaudhry Muhammad Nadeem Faisal ${ }^{1}$, Muhammad Shakeel Faridi ${ }^{2}$, \\ Zahid Javed $^{2}$, Muhammad Shahid ${ }^{1}$ \\ ${ }^{1}$ Department of Computer Science, National Textile University, Faisalabad, Pakistan \\ ${ }^{2}$ Department of Computer Science, University of Agriculture, Faisalabad, Pakistan \\ Email: \{cmn.faisal, m.shahid\}@ntu.edu.pk, \{shakeelfaridi, zahidjaved.uaf\}@gmail.com
}

Received March 2, 2012; revised April 8, 2012; accepted April 15, 2012

\begin{abstract}
Generically system includes two types of categories, computerized based system and socio-technical system; the difference between both types of systems is that the socio-technical systems deals with technical operation and involves the users. Information system that deals with the flow of information regarding business and social perspective falls in socio-technical based system. ERP (Enterprise Resource Planning) is the best example of Information system that organization adopt to make fast the business process. The ERP systems are suffering from multifaceted interface. Previous research shows that there is a need for an improvement regarding user interface because it is the way of communicate with system. As the emphasis of HCI (Human Computer Interaction) is to clearly understand the users' philosophy, reminiscence and problems solving technics in order to design users oriented applications. Therefore the usability engineering is the only way to study the deeds of users by getting analysis on prototype or system by offering different methods and techniques. This paper will focus on the users' experiences in view of financial module in ERP system which is based on different sub-components. To carry this research work HCI research methods, automated explicitly survey questionnaire method and focus group were adopted to gather users understanding in order to evaluate the selected application in ERP system. This study involved group of users from various corporate level industries in textile sector. It is the extended work as in previous only two industries were selected.
\end{abstract}

Keywords: Enterprise Recourse Planning; Human Computer; Interaction; Usability Engineering; User Interfaces

\section{Introduction}

The ERP can be defined as package, components and sub-components of business applications. The reason for the integration of these components is to manage the business processes that carry the fast flow of information within organization internally and externally [1,2]. These corporate systems are enlarged with functionality and offer significant benefits to improve the operational efficiency in organization and it also manage the linking with the stakeholders [3,4]. ERP includes software for manufacturing; order tracking, payable and receivable accounts, general ledger, purchase \& inventory, warehousing, transportation and human resources. In spite of significant benefits, ERP system always been criticized due to complexity. Complexity is only because of integration of different business applications and also to process huge data. The richer or multifaceted systems can provide less effective functionality if they have huge usability problems $[4,5]$. Furthermore the functionality and complexity corporate system persuade the confusion, frustration and failure with negative responses toward users, thus which leads mistake while working on such applications $[4,6]$. Therefore there is requirement to de- liver user interfaces that are easy to use, learnable, remember able and support the users in their anticipated tasks. As small improvements in usability of ERP system can bring large benefits [4,7]. Partial work is available that highlight the usability issues on ERP that intent the authors focus towards this. This research work includes the following objectives: To evaluate effectiveness of selected application in ERP system from users' perspective and to identify the current practices of Usability for software development and the impact of ERP systems capabilities on managers' decision making abilities. The evaluation is based on a case study in three textile Industries. Investigation is carried out according to the HCI parameters, using automated survey and focus group from users were selected non-randomly during the whole assessment. The research paper comprises the following sections: Sections 1 and 2 contain a discussion of related work in terms of measuring common system usability. A set of usability criteria, which is used to identify the usability issues in and empirical work Section 3, Section 4 data gathering and analysis during empirical work. This is followed by finding, conclusion (Sections 5, 6), while at the end list of references. 


\section{What Is Usability}

System plays important by developing new technologies that support the users in various contexts. The dominancy of interactive system in computing paradigm because of its technologic nature to supported the users in every field of life. Usability testing is used to evaluate such interactive technologies. It not deals the functional specifications delivered by the system but it is related to the emergent system properties, features and system interface. So usability is a discipline that helps the investigator to uncover the usability related issues and to improve the usability of the product. Generally, these are the following three types of usability evaluation methods: testing, inspection, and inquiry.

\subsection{Usability Testing [8-10]}

In usability testing approach the users have to work on the precise tasks based on defined scenarios using system or system prototype. It includes: Coaching Method, Codiscovery Learning, Performance Measurement, Questionasking Protocol, Remote Testing, Retrospective Testing, Shadowing Method, Teaching Method, and Thinking Aloud Protocol.

\subsection{Inspection [8,9]}

In usability Inspection approach, the usability specialist, software developer, designers, users and experts examine usability related harms or feature in a user interface. It includes the following techniques. Cognitive Walkthroughs, Feature Inspection, Heuristic Evaluation, Pluralistic Walkthrough, and Perspective-based Inspection.

\subsection{Inquiry $[8,9]$}

In usability Inquiry approach, the usability evaluators gather the information from users about their likes, dislikes, needs, and understanding of the system by observing and letting them answer questions verbally or in written form. It include strategies: Field Observation, Focus Groups, Interviews, Logging Actual Use, Proactive Field Study, and Questionnaires.

\subsection{Commonly Used Assessment Criteria [11-17]}

The Usability evaluation of such socio-technical systems are very much complex because of limited and varied criteria. Mostly adopted parameters to evaluate the user interface are as given below. Ease of use, usefulness, task support, learnability, memorability, presentation, help and support, navigation, guidance, flexibility, customization, completeness, reliability, system responsiveness and system response time.

\section{Empirical Work}

Usability discusses different attributes of system from user's point of view. Primarily usability survey method was adopted as it is cost effective and efficient way to gather the data from participants while concerning the usability testing it is reasonably difficult for authors to perform usability test because of following constraints time, obligatory resources and participants' unwillingness usability testing. The survey includes the rating scale for evaluation. To assess the ERP system, automated survey method was developed using Oracle. The automated survey tool was integrated with HR module in ERP. The purpose of integration is due to control the users' demographic qualities and uniqueness. Steps involve in conducting a survey using automated tool.

1) Survey was designed and developed within Oracle on 32 bit operating system.

2) All questions were based on usability criterion.

3) 50 users related to the application in ERP were selected non-randomly for assessment purpose.

4) For the evaluation of ERP system, the financial module was selected.

5) Link of questionnaire was sent to the selected participants and users had to rate usability questions from the given values accordingly or perceived.

\section{Analysis}

The Criterion at which assessment methods was designed is shown in Table $\mathbf{1}$ and selection of swaying attributes were based on literature given by (Chin et al., 1988, Davis, 1989, Nielsen, 1993, Lewis, 1995, Perlman, 1997, Akash Singh, Evaluation Criteria for Assessing the Usability of ERP, SAICSIT'09, 12-14 October 2009, Riverside, Vanderbijlpark, South Africa Systems) and industrial inspection. The assessment tool comprises 40 statements that users have to rate accordingly.

Responses' received from users and were stored in Database that is administrating by the IT department of MTM. The users have to answer the question as per value they perceived from the chosen module at their work. So this regards 50 mangers were preferred and from them 31 have more than 3 years' experience whereas 19 mangers have less than 1 year experience in industry. 39 out of 50 have master level qualification while remaining 11 are charted accountants. The authors received the response from all 50 users precisely and completely. Figures 1-2 shows the strongly agrees (5) and agree (4) responses. Figure 3 shows natural (3) responses. Similarly Figures 4-5 shows disagree (2) and strongly disagree (1) number of responses against usability assessment criterion.

\section{Finding}

The purpose of this work is to evaluate the ERP system, from users' outlook. The primary intent is to reduce the cost of training for novice and new users, to identify the 
Table 1. Selected criteria for assessment.

\begin{tabular}{|c|c|c|}
\hline SN & CRITERIA & ATTRIBUTES \\
\hline 1 & Usefulness & $\begin{array}{l}\text { 1. It helps me to be more effective } \\
\text { during working; } \\
\text { 2. It helps me to be more productive; } \\
\text { 3. I would find the system useful in my job; } \\
\text { 4. It makes the things I want to accomplish eas- } \\
\text { ier to get done; } \\
\text { 5. It saves my time when I use it; } \\
\text { 6. It meets my needs and requirements; } \\
\text { 7. It does everything I would expect it to do; } \\
\text { 8. Using the system would improve my job } \\
\text { performance; }\end{array}$ \\
\hline 2 & Ease of Use & $\begin{array}{l}\text { 9. It is easy and simple to use; } \\
\text { 10. It is user friendly; } \\
\text { 11. It requires the fewest steps possible; } \\
\text { to accomplish what I want to do with it; } \\
\text { 12. It is flexible and Using it is effortless; } \\
\text { 13. My interaction with the system would be } \\
\text { clear and understandable; } \\
\text { 14. I can use it without written instructions; } \\
\text { 15. I can recover from mistakes quickly and easily; } \\
\text { 16. I can use it successfully every time; } \\
\text { 17. Training time is sufficient to understand all } \\
\text { the aspect; }\end{array}$ \\
\hline 3 & $\begin{array}{l}\text { Easy of } \\
\text { Learning }\end{array}$ & $\begin{array}{l}\text { 18. I learned to use it quickly; } \\
\text { 19. It is easy to learn to use it; } \\
\text { 20. I easily remember how to use it; } \\
\text { 21. I quickly became skillful with it; }\end{array}$ \\
\hline 4 & Satisfaction & $\begin{array}{l}\text { 22. It is fun to use; } \\
\text { 23. I am satisfied with it; } \\
\text { 24. It is easy to use; } \\
\text { 25. It works the way I want it to work; } \\
\text { 26. It is wonderful; } \\
\text { 27. I feel I need it for job; } \\
\text { 28. It is pleasant to use; }\end{array}$ \\
\hline 5 & Efficiency & 29. Overall Efficiency of the system; \\
\hline 6 & Memorability & 30. Overall memorability of the system; \\
\hline 7 & $\begin{array}{l}\text { Error } \\
\text { Prevention }\end{array}$ & 31. Errors (Accuracy) of the system; \\
\hline 8 & Aesthetic & $\begin{array}{l}\text { 32. Arrangement of Color on Screen are beauti- } \\
\text { ful; } \\
\text { 33. Arrangement of Text on Screen is visible; } \\
\text { 34. Graphically application is nice and attractive; } \\
\text { 35. User Interface is Customizable or are you eli- } \\
\text { gible to change the menu bar or button; }\end{array}$ \\
\hline 9 & $\begin{array}{l}\text { Help \& } \\
\text { Support }\end{array}$ & $\begin{array}{l}\text { 36. How fast feedback in system; } \\
\text { 37. Error messages provides information about the } \\
\text { error or cause of error; }\end{array}$ \\
\hline 10 & $\begin{array}{l}\text { Decision } \\
\text { Making }\end{array}$ & $\begin{array}{l}\text { 38. Is System provides information for; } \\
\text { 39. Is System provides information for better deci- } \\
\text { sion making; }\end{array}$ \\
\hline 11 & $\begin{array}{l}\text { Knowledge } \\
\text { Ability }\end{array}$ & $\begin{array}{l}\text { 40. ERP System provides me information and also } \\
\text { help in documentation; } \\
\text { 41. System allow me to enter my daily experience, } \\
\text { tasks or problems, that I faced during working time } \\
\text { in office; } \\
42 \text {. The system provide me knowledge to solve the } \\
\text { problem. }\end{array}$ \\
\hline
\end{tabular}

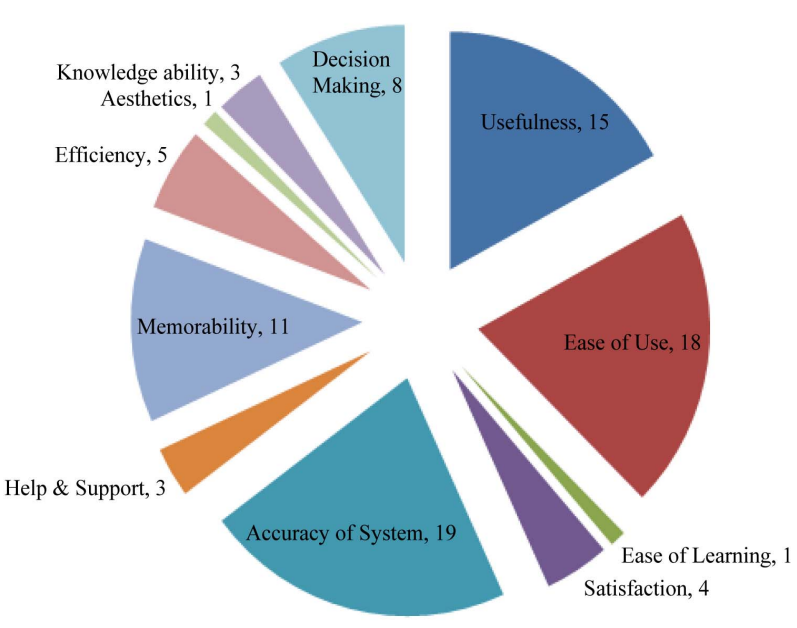

Figure 1. Showing the responses toward strongly agrees.

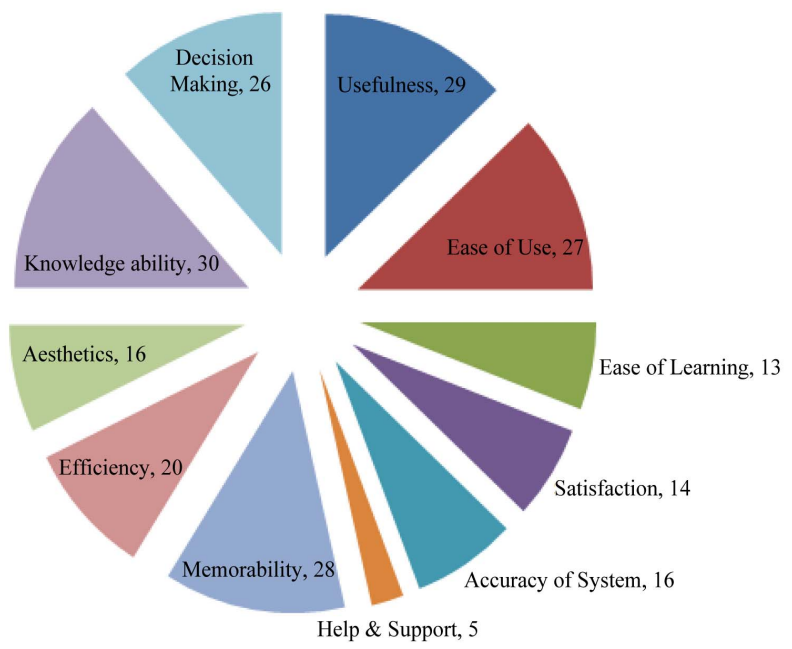

Figure 2. Showing the responses toward agrees.

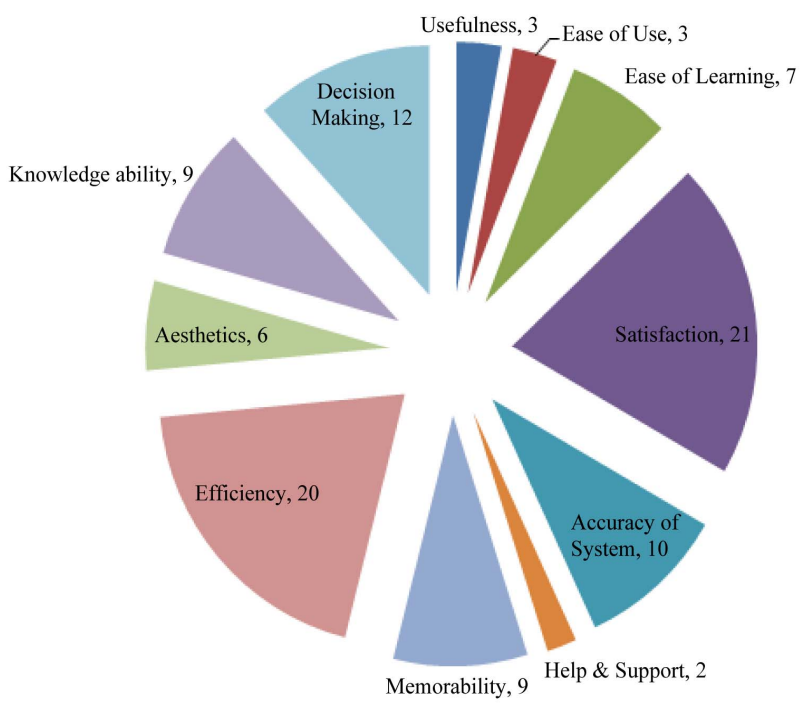

Figure 3. Showing the neutral responses. 


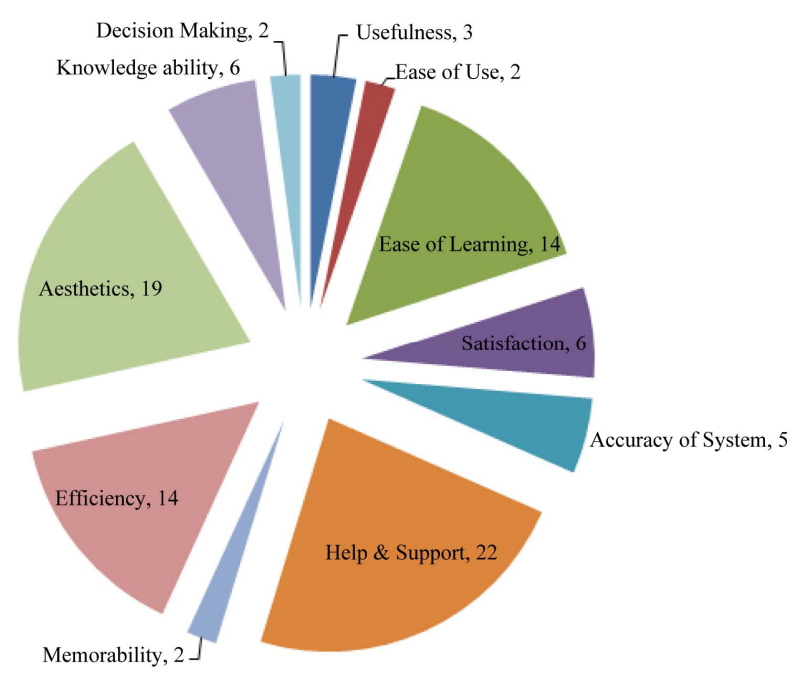

Figure 4. Disagree responses.

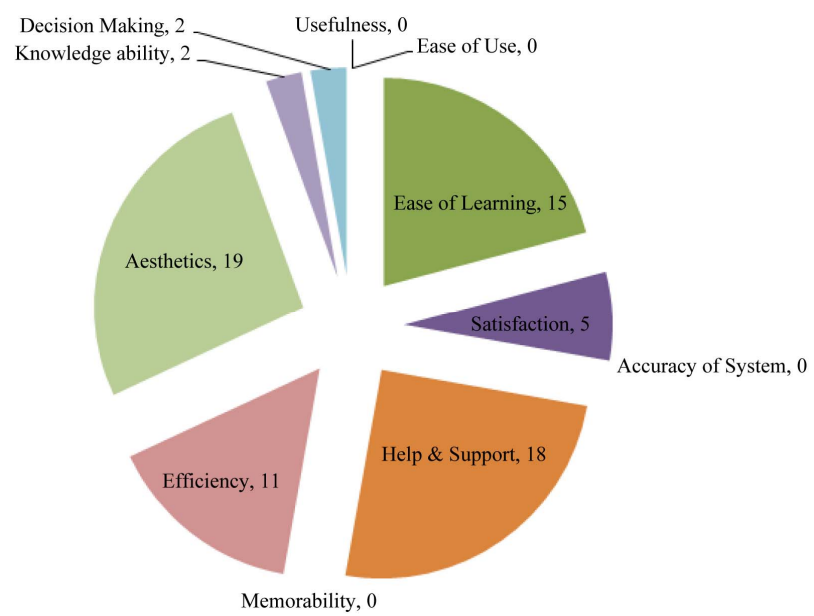

Figure 5. Strongly disagree responses.

existing practices of usability for software development and the impact of ERP capabilities on managers in decision making skills. The assessment was based on precise criteria with HCI (Human Computer Interaction) parameters using usability assessment tool. After assessment, it was found that majority of participants gets problems in 3 (Easy of learning), 5 (Efficiency), 8 (Aesthetics) and 9 (Help and Support).

$$
\mu=\frac{\sum_{i=1}^{n} \mathrm{x}_{i}}{\mathrm{n}}, \quad \sigma_{M}=\frac{\sigma}{\sqrt{\mathrm{N}}}
$$

Standard error of means against 3, 5, 7, and 8 are 2.646, 2.946, 3.302 and 4.159 respectively. Results taken from the whole investigations a show that, the selected applications does not provides the sufficient help and support in documentation to users to improve the learnability for system. The graphic wisdom of the software is not attractive and good to involve the users thru time of interaction with the ERP system. Thus the issues and problems that arise in learnability is only due to lack of help and support in the ERP and which is the main cause for that the industry has to spend enough time and cost for training. Similarly novice and new users have spent their time and efforts to develop the understanding with the interfaces of ERP system. According to the statistics analyzed from automated survey method also shows that ERP systems are very useful and provides help to the manager and users in making decision with sufficient knowledge in certain conditions towards better decisions. But knowledge and information provides selected application is very specifics that cover the limited decisions about the working. The statistics also shows interface of the sleeted application is poorly arranged that alternately affect the user performance and efficiency. As the results the investigation shows that by the improving the usability of information system not only enhances users' productivity but also provides them efficient working environment for personal growth. This study conducted on a group of users in textile industry but does not represent the whole sample size consequently the results are very much specific.

\section{Conclusion}

This research was basically a contribution to the assessment of corporate system as it is the mostly common used application for workers in an organization and for this an assessment of existing ERP system conducted through inquiry tool from a group of users under the specified criteria. In usability survey method, Corporate level Users from different industries had to rate the questions. Findings are towards the cost of training and intricacy in ERP systems just because of massive information and fast operations. In Pakistan where the workforces are not very much conscious about the information technologies takes time to comprehend such applications consequently the corporations have to spent time and money for trainings. Furthermore In-house development sides are not very much conversant with HCI and usability engineering which is the major cause of poor usability of ERP system in Pakistan. The Enterprise resources planning systems are the backbone of organizations to assimilate and form opportunities for business and also to support the cross functional activities. Organization stresses for good ERP system to see their business requirements. These chucks only fulfill when such business information system will be designed and develop functionally and non-functionally accurate. Thus to fulfill the non-functional requirements it is essential to involve the users at early stage of development. The basic objective of this research is to identify the usability issues, practices and adoptive behavior of users towards in-house developed ERP system. 


\section{REFERENCES}

[1] Boudreau, "Marie-Claude Boudreau, Learning to Use ERP Technology: A Causal Model,” 36th Annual Hawaii International Conference on System Sciences (HICSS’ 03)—Track 8, Big Island, 6-9 January 2003. doi:10.1109/HICSS.2003.1174611

[2] J.-Y. Yeh, "Evaluating ERP Performance from User Perspective,” IEEE Asia-Pacific Conference on Services Computing (APSCC '06), Guangzhou, December 2006, pp. 311314.

[3] N. C. Goodwin, "Functionality and Usability," Communications of the ACM, Vol. 30, No. 3, 1987, pp. 229-233. doi:10.1145/214748.214758

[4] I. Ceaparu, J. Lazar, K. Bessiere, J. Robinson and B. Shneiderman, "Determining Causes and Severity of End-User Frustration,” International Journal of Human-Computer Interaction, Vol. 17, No. 3, 2004, 333-356. doi:10.1207/s15327590ijhc1703_3

[5] P. W. Jordan, “An Introduction to Usability,” Taylor and Francis Ltd., Oxford, 1998, pp.1-7.

[6] L. Hohmann, "Usability: Happier Users Mean Greater Profits,” Information Systems Management, Vol. 20, No. 4, 2003, pp. 66-76. doi:10.1201/1078/43647.20.4.20030901/77295.10

[7] A. Singh, "Improving the Usability of ERP Systems through the Application of Adaptive User Interfaces," Proceedings of 11th International Conference on Enterprise Information Systems (ICEIS), Milan, 12-14 October 2009, pp. 87-88.

[8] F. Calisir, "The Relation of Interface Usability Characteristics, Perceived Usefulness, and Perceived Ease of Use to End-User Satisfaction with Enterprise Resource Planning
(ERP) Systems,” Computers in Behavior, Vol. 20, No. 4, 2004, pp. 505-515

[9] C. M. Nadeem Faisal, "Usability form Industrial Pro- spective,” 2012. https://files.itslearning.com/data/640/8517/papers/3.pdf

[10] Chaudhry Muhammad Nadeem Faisal, "Usability Evaluation of In-Housed Developed ERP System,” 2011 International Conference on Graphic and Image Processing, Cairo, 1-3 October 2011. doi:10.1117/12.913212

[11] L. Herbert, "Put Business Applications to the Usability Test,” Forrester Research, Cambridge, 2006.

[12] Keystone Strategy Inc., "ERP End-User Productivity: A Field Study of SAP and Microsoft,” Microsoft Dynamics, 2007.

[13] D. Matthews, “Usability as ERP Selection Criteria,” 2008. http://ifs.datahost.com/shop/images/wp-usability.pdf

[14] SAP Design Guild, “User Day Toolkit,” 2004. http://www.sapdesignguild.org/resources/user_day_toolki t/index.htm

[15] J.-H. Wu, "Development of a Tool for Measuring Key-User Satisfaction in an ERP Environment," Proceedings of the 6th Pacific Asia Conference on Information Systems (PACIS), Tokyo, 2-4 September 2002, pp. 555-568.

[16] W. O. Galitz, "The Essential Guide to User Interface Design, an Interdiction to GUI Design Principles and Technique,” Jhone Wiley and Sons, 2002, pp. 55-717.

[17] C. M. Nadeem Faisal, "Usability Evaluation of Cloud Based Application,” Department of Interaction and System Design School of Engineering Blekinge Institute of Technology, Sweden, 2009. 